University of Louisville

ThinkIR: The University of Louisville's Institutional Repository

Electronic Theses and Dissertations

1948

\title{
The dye-dilution method for measuring the volume of circulating plasma.
}

David T. Overbey 1920-2001

University of Louisville

Follow this and additional works at: https://ir.library.louisville.edu/etd

Part of the Medicine and Health Sciences Commons

\section{Recommended Citation}

Overbey, David T. 1920-2001, "The dye-dilution method for measuring the volume of circulating plasma." (1948). Electronic Theses and Dissertations. Paper 2124.

https://doi.org/10.18297/etd/2124

This Master's Thesis is brought to you for free and open access by ThinkIR: The University of Louisville's Institutional Repository. It has been accepted for inclusion in Electronic Theses and Dissertations by an authorized administrator of ThinkIR: The University of Louisville's Institutional Repository. This title appears here courtesy of the author, who has retained all other copyrights. For more information, please contact thinkir@louisville.edu. 


\title{
UN IVERSITY OF LOUISVILIE
}

\section{THE DYE-DILUTION METHOD FOR MEASURDNG THE VOLUME OF CIRCULATING PIASMA}

\author{
A Dissertation \\ Submitted to the Faculty \\ of the Graduate School of the University of Louisville \\ In Partial Fulfilimont of tho \\ Requirements for the Degree \\ Of Master of Science
}
Department of Physiology
By

David T. Overbey

1948 
THE DYE-DILUTION METHOD FOR MEASURTNG THE VOLUME OF CIRCULATING PLASMA

\section{2}


TABLE OF CONTENTS

Page

THTRODUCTION................................ 1

PART I

INTRODUCTION............................. 3

METHODS.................................. 6

RESULTS................................. 9

DISCUSSIOH.............................. 22

PART II

INTRODUCTION..............................26

METHODS................................. 28

RESULTS................................ 31

DISCUSSION............................... 36

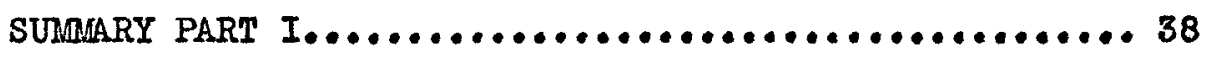

SUMARY PART II.......................... 40

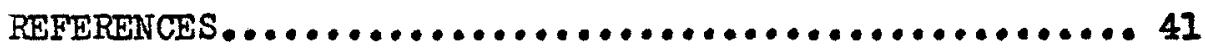




\section{AC KN OWLEDGEMENT}

I acknowledge with pleasure my gratitude to

Dr. Hampden Laws on for the suggestions he has made, and the interest ho has show, during this study. I also wish to express my appreciation to Dr. J. C. Moore and Dr. O. W. Shadle who performed some of the experiments presented in this thesis, and to the other members of the Department of Physiology and Pharmacology for their advice and criticisms. 
INTRODUCTION 
The usual "Indirect Methods" for estimating blood volume may be divided roughly into three types: (1) The measurement of total intravascular hemoglobin from its percentage combination with foreign gases such as co. (2) The dilution volume of red blood cells tagged in various ways. (3) The dilution volume of dyes and other substances which are assumed to distribute themselves through the same volume as plasma.

The first two methods theoretically measure the circulating red cell volume. This volume and the cell-plasma ratio may be used with appropriate formulas to estimate the plasma volume and total blood volume. The third method theoretically measures the plasma rolume and this, with the cellplasma ratio and appropriate formulas, may be used to estimate total blood volume.

The foreign gas method has generally fallen into ill repute, partly because of the many possible sources of error and also due to the technical difficulty in using the mothods. The tagged-red cell method, when radioactive isotopes of iron are used for tagging, presents the fewest theoretical objections, and values obtained by this method for red cell volume are probably the most accurate ones available. However, this method requires the use of expensive equipment and determinations are very time consuming. Furthermore, radioctive isotopes are not generally obtainable: The third method is by far the most widely used at present. The toludine dye T-1824 is used by most observers working with this mothod because it has been shown to combine with the plasma albumins. It has been assumed that the plasma albumins remain within the cardiovascular compartment because of their molecular size. 
The work presented in this paper was undertaken in an effort to analyze critically the dye dilution method. For the sake of clarity the material has been divided into two parts as follows:

I -A- A study of the mixing of cells, plasma, and the dye T-1824 in the cardiovascular system of barbitalized dogs.

-B- A critical examination of the rate of disappearance of the dye T-1824 from arterial blood.

II

The measurement of plasma volume as distribution volume of injected autogenous plasma.

In part I qualitative and quantitative studies were made of dye concentrations and cell-plasma ratios in arterial blood following various experimental procedures, while in part II ooll, plasma, and blood volumo determinations were made with the use of appropiate formulae. Plasma volume in part II was critically examined in the light of the findings which were made in part $I$. 
INTRODUCTION

PART I 


\section{INTRODUCTION}

\section{PART I}

When substances, which theoretically distribute themselves in the circulating blood volume, are injected into the cardiovascular system, some finite time must be required for mixing of the substance with the blood volume. It is necessary to know when mixing is complete in order to determine blood volume from the dilution volume of the injected substance or substances. When the mean velocity of blood flow is great the "mixing time" should be shorter then when the mean velocity of flow is small, provided, of course, that there are no circuits with extremely slow flow in the one case and not in the other. As Erlanger has pointed out, mixing with the entire volume of blood cannot be complete, however, until the slowest vascular circuit has been transversed at least once. "rixing" of a substance in the cardiovascular system is therefore not complete until the concentration of tine substance is the same in all parts of the cardiovascular system.

Most studies on "mixing" of substances in the cardiovascular system have been made with vital dyes. When vital dyes which presumably measure plasma volume, are injected into the cardiovascular system three distinct phases in concentration-time relationships occur in blood drawn from large vessels. The first phase is one characterized by rapid oscillations of concentration and usually is complete within two minutes. This is assumed to be caused by divisions and recombinations of the injected substance which enters the cardiovascular system as a short colum practically unmixed with blood. This phase ends when the substance is homogeneously distributed in blood oirculating through the heart, lungs, and great vessels. (Stewart, 1921; Hamilton, Moore, Kinsman, and Spurling, 1928). In plasma volume determinations, as used generally, samples are not drawn in this 
phase. This phase was not studied.

The second phase is one characterized by relatively rapidly falling concentration of injected substance. This period usually lasts from five to twenty-five minutes and has generally been assumed (Gibson and Evans, Gregerson, et al) to be caused by slow mixing in the slower moving circuits in the cardiovascular system. This is generally called the "mixing curve". The time from the instant of the injection to the end of this phase is called the "mixing time". The most widely accepted theory is that mixing is complete at the end of the second phase.

The third phase is one in which the concentration of injected substance falls slowly with time. This is thought to be caused by removal of the injected substance. This phase of slowly falling dye concentration appears to ba a logarithmic function of time. The most widely used method for determining plasma volume requires the extrapolation of this phase of slowly falling dye concentration back to the time of injection. This theoretically demonstrates the concentration of dye which would be present if no disappearance had occurred. Since this method was popularized by Gibson and Evans it will be referred to in this paper as the Gibson and Evans Hothod (abbreviated, G. \& E. Hethod).

A few studies have been made on the apparent "mixing time" of red cells tagged with radioactive isotopes. These show an absence of a "mixing curve" in both dogs and rabbits after four minutes and usually after two minutes. Hahn and Heresy (1940) found no evidence of mixing of red cells tagged with $\mathrm{P}^{32}$ in the rabbit after two and one-half minutes. Hahn, Ross, Balo, Balfour, and Whipple, using red cells tagged with radioiron, found no evidence of continued mixing after about four minutes in the dog. A systemic study was undertaken of the "mixing time" for the dye $\mathrm{T}-1824$, 
red blood cell suspensions, and plasma, both dyed and undyed. Except for the study of "mixing time" with the dye alone, relatively large volumes were used. This required the use of a large number of different controls. The results of these experiments brought up the possibility that the second or socalled "mixing curve" for T-1824 might represent disappearance of dye from. the cardiovascular system rather than mixing within it. As a result a critical examination of the disappearance of T-1824 from arterial blood was made. 
METHODS 
METHODS

Dogs, splenectomized soon after induction of sodium barbital anesthesia (250 mgm/ $\mathrm{kg}$ ), and under anesthesia for at least three hours, were used throughout these studies.

Mixing time for red cell injections was determined by following the changes in arterial hematocrit produced by the infusion of red cell suspensions of sufficient volume to increase the arterial hematocrit 15 to $35 \%$ The cell suspensions were freshly prepared by centrifuging heparinized dog blood and removing the supernatant plasma. The cell suspensions had an hematocrit in the neighborhood of $90 \%$ Injections were made as rapidiy as possible through a wide cannula tied in a femoral vein. The time required was usually around ten to twonty seconds and approximately $10 \mathrm{cc} / \mathrm{kg}$ were injected. Samples of arterial blood were obtained from a brachial artery cannulated distal to the profunda brachil. Blood was drawn through needle tubing directly into winthrobe tubes containing measured amounts of axalate solution. Before sampling the line was cleared each time by bleeding about $0.5 \mathrm{cc}$. This was two or more times the volume of the cannula and bleeding line. The samples were stirred with a sma 11, dry motal rod to insure against clotting. They were then capped and spun in a centrifuge at $2,600 \mathrm{R}$. $P$. Mo in a radius of $20 \mathrm{~cm}$. for ono hour. After deduoting the oxa late present in each tube, the hematocrits were calculated as 0.92 times the observed hematocrit, in order to correct for trapped plasm (Chapin and Ross).

The "mixing" of injected plasma with circulating cells was studied by noting the change in hematocrit with time after injection of approximately $10 \mathrm{cc} / \mathrm{kg}$. of plasma. "Mixing" of injected plasma with the circulating 
plasme was studied by oither dying the circulating plasma (with T-1824) and determining the decrease in optical density following the injection of undyed plasma, or by dying the injected plasma and noting the increase in optical density. All plasme injections were made with autogenous plasma since it was found that in vitro mixtures of plasmas (both dyed and undyed) from different dogs usually did not give the expected optical density for the mixtures. Autogenous plasma was prepared by bloeding the animal soon after induction of anosthesia and roplacing with an equal volume of donor blood. Plesma obtained from the autogenous blood when mixed in Vitro with plasma obtained from the same animal three or more hours later. gave optical densitios in good agreement with the expected values.

In some of the experiments the blood rolume was expanded by injections of approximately $10 \mathrm{cc} / \mathrm{kg}$. of dyed autogenous plasma, undyed autogenous plasma, or red cell suspensions. In other experiments an attempt was made to keep blood volume constant by hemorrhaging rapidly through a large bleedIng cannula tied in a feroral artery a volume equal to the replacemont. The time required from beginning of bleeding to end of the replacement was less than ane minute.

The time-arterial concentration relationships of $T-1324$ were studied as follows:

1. Effect of an initial dye injection (high concentration in sma 11 volume) on time-arterial optical density relationships of a second dye injection (high concentration in small volumo).

2. Effect of initial dye injection (high comcentration in small rolume) on time-arterial optical density relationship of a second dye injection (low concentration dye in autogenous plasma) with blood volume constant.

3. Effect of initial dye injection (low concentration dye in autogenous plasma) on time-arterial optical density relationships of a second dye injection (high concentration in small volume) with blood rolume constant. 
4. Effect of initial dye injection (high concentration in small volume) on time-arterial optical density relationships of autogenous plasme (undyed) infusions made at varying lengths of time following the first injection. The blood rolume was kept canstant by rapid hemorrhage and infusion of equal volume.

Plots of time-optical density relationships were made with linear. semi-logarithmic and full logarithmic coordinates. Dyo in plasma was usually expressed in terms of optical density but in some cases was expressed as dye concentration. 
RESULTS 
I Mixing of cells as compared to that of dye

Representative data on cell mixing are shown in Figure 1 . In experiment A of the figure, dye was added to the cell concentrate before injection, in order to obtain simultane ous disappearance curves for dye and cells. It is readily apparent that there is an absence of the socalled "mixing curve" as far as the red cells are concerned. The arterial hematocrit was raised about $32 \%$ in this case. The injected dye, however, showed a characteristic "mixing curve". In experiment B, the dye and cells were injected separately, the dye in $10 \mathrm{cc}$. solution, in order to make sure that the optical density was due to dye alone. In experiments $A$ and $B$, a rapid hemorrhage of equal volume preceded the cell infusion so that total blood volume remained relatively unchanged.

Arterial hematocrits were taken at one minute intervals in eleven experiments following cell suspension infusions. In six of these, mixing was apparently complete within one minute since the one minute hematocrit and those immediately following showed only random deviations from the post-injection mean and no progressive changes of hematocrits could be detected. In two experiments, cell mixing periods of two and three minutes respectively occurred. In the three remaining experiments, there was a progressive rise in hematocrit lasting for three minutes. This is opposite from the expected curve for mixing. Ten additional experiments were performed with samples taken at three minute intervals following injection of cell concentrates. In none of these is the first value high. The maximum time for apparent "mixing" of injected cells, as deternined from the change in hematocrit, was three minutes in a series of twenty-one experiments. 

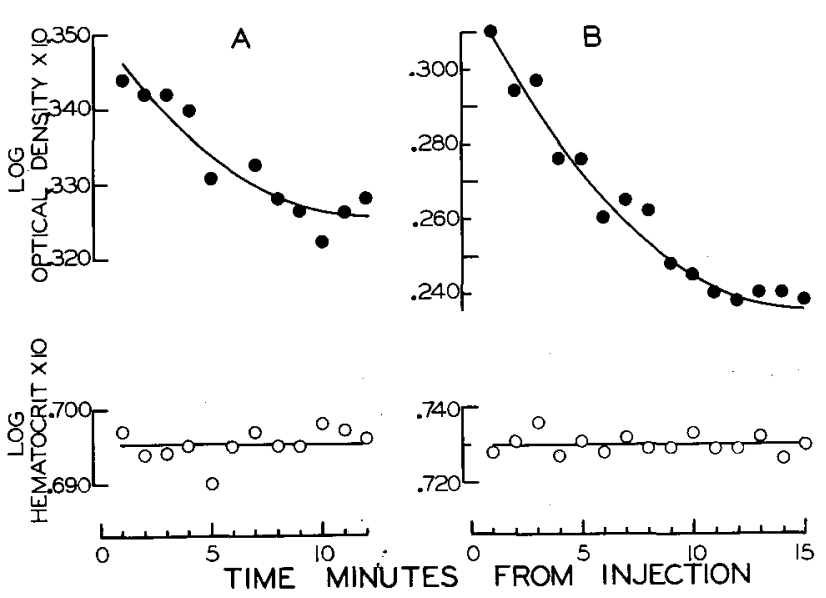

Figure 1. A. Dye concentrations and hematocrits following injection of dyed cell suspension. Intravenous injection at tim 0 of $80 \mathrm{cc}$. cell concentrate containing $10 \mathrm{mg}$. T. 1824.

Control hematocrits average 0.375 (not shown in figure). Lino drawn through post-injection hematocrits at average equals 0.496 (antilog.). Dye concentration given as optical density against undyed plasma reference. Semi-logarithmic plot for both optical density and hemetocit.

B. Consecutive injections of $10 \mathrm{mg}$. dye (upper curve) and 100 cc. cell concentrate (lower curve). Construction of figure as in A. Average hematocrit before coll concentrato injection equals 0.481 , after injection equals 0.537 (antilogs.) 


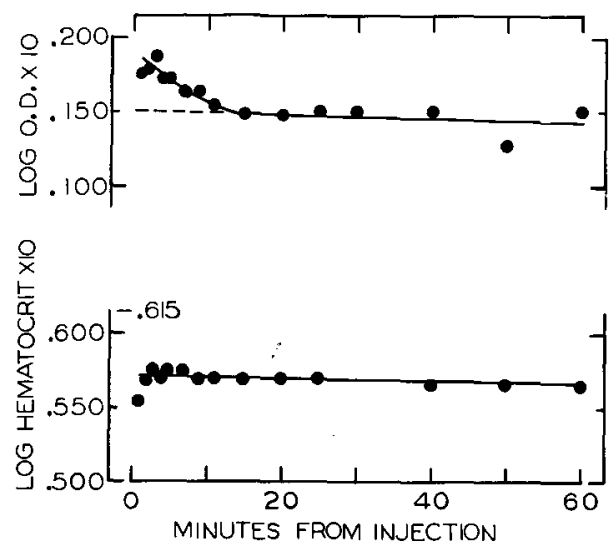

Figure 2. Dye concentrations and hematocrits following injection of dyod plasma. Intravonous injection at time 0 of $100 \mathrm{cc}$ plasma containing 10 mgm. T-1824. Semi-logarithmic plot of subsequent hematocrits (lower curvo) and plasm dyo concentrations as optical density (upper curve). Pre-injection hematocrits averaged 0.412 , post-injection values at two to nine minutes average 0.371 (antilogs.). 
II -Mixing of dye as compared to that of plasma

Figure 2 shows the logarithm of optical density and the logarithm of hematocrit plotted against time in an experiment where dyed autogenous plasma was rapidly infused. Total blood volume was kept relatively constant by rapidly withdrawing an equal volume of blood just before the infusian. The typical "mixing curve" can be seen in the log. optical density- $L$ time plot. If the rapidly falling dye comcentration were due to loss of the dyed plasma to slower peripheral vascular circuits, a rising arterial hematocrit would be expected to occur during the same period. No rise in arterial hematocrit occurs after the second minute. If dyed plasma were lost thereafter to the slowly moving circuits, it must have carried cells with it so that the cell-plasma ratio of the blood leaving was the same as that in the central circulation. Fourteen experiments of this type have been performed; half of them with a bleeding preceding the dyed plasma injection. Hematocrit data have been obtained in nineteen experiments after injection of undyed plasma. The longest time for the progressively rising hematocrit curves was five minutes in the entire series of thirty-three experiments (one animal). In over half of the experiments there was no curve seen at all or the curve was completed in two minutes. The average duration of the curve was somewhat longer for the experiments not preceded by bleoding than for those in which it was dome. III -Comparison of "mixing curves" for dye, dyed plasma, and undyed plasma as determined by $10 g$ optical density-time plot.

In part $A$ of Figure 3 an initial injection of dyed plasma was made $\left(A_{1}\right)$ giving a fairly typical "mixing curre". A subsequent injection of dye in saline was made $\left(A_{2}\right)$ and again a typical mixing curve was obtained. Part $B$ represents another experiment in which an initial injection of dye in saline $\left(B_{1}\right)$ was made. This gave a typical "mixing curve". This was followed by a 


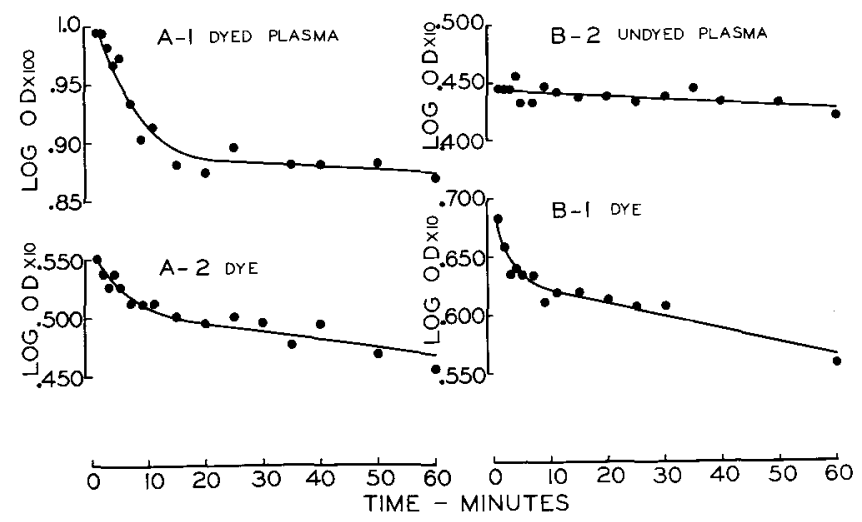

Figure 3. A. Dye concentrations following injoction of dyed plasma (upper curve. A-1) and aque ous dye solution (lower curve. A-2), in same animal. Dyed plasma injected in volume of $100 \mathrm{cc}$, containing 3.5 mg. T-1824, Immediately preceded by $100 \mathrm{cc}$. bleeding. Aque ous dye solution given one hour later, volume $10 \mathrm{cc}$, containing $10 \mathrm{mg}$. dyo. Semi-logarithmio plot both curves. Dye concentrations as optical density.

B. Dye concentrations following injection of undyed plasma (upper curve, B-2), in dyod animal. Lower curre, $B-1$, shors injection of $20 \mathrm{mg}$ - dye in $20 \mathrm{cc}$. aqueous solution, one and one-half hours earlier (last thirty minutes of curve not plotted). Plasma injected in volum of $90 \mathrm{cc} .$, preceded by bloeding of equal volume. Construction of figure as in A. 
rapid hemorrhage and replacement with an equal volume of undyed plasma. If the falling optical density in $A_{1}$ represents the mixing of injected dyed plasma with the sluggish peripheral circuits, there should be a similar curve following injection of undyed plasme. Mixing should then be represented by a rising optical density as the dyed plasma in the slow circuits flows into the central circulation and is replaced in the slower circuits by plasma with a low optical density. No such "mixing curve" can be seen in $\mathrm{B}_{2}$, the values from one minute onward falling on the same slope for a full hour. Undyed plasma was injected into dyed animals in nineteen experiments of this sort. In twelve of these, the injection was preceded by bleeding. In most cases with the bleeding no curve of rising optical density could be made out if the first sample was drawn at one minute. Such curves were usually present if the bleeding was omitted. However, in no case was the duration of the "mixing curve" over five minutes. In contrast the usual duration of the "mixing curve" for dyed plasma or dye in saline was in the neighborhood of ten minutes in the majority of our experiments, with a maximum of twenty minutes.

The foregoing data indicate that mixing of plasma and cells is complete in all cases within five minutes and usually within two to three minutes. The so-called "mixing curve" for dye was usually of the order of ten minutes. It seems that the "mixing curve" for dye represents some process which does not occur to plasme or cells and, therefore, represents something other than just "mixing"within the cardiovascular system. A study of the rates of disappearance of the dye from arterial blood was made in order to obtain information concerning the meaning of the dye "mixing curges". Dye was injected in saline in 10-20 mgm. doses intravenously. This usually produced plasma dye concentrations between 0.01 and $0.03 \mathrm{mgm} / \mathrm{cc}$. 
IV - Comparison of linear, semi-logarithmic and full logarithmic plots of optical density-time relationships in arterial plasma following rapid intravenous injection of $\mathrm{T}-1824$ in saline.

Figure 4 shows the time-optical density relationships following a rapid intravenous injection of $T-1824$ plotted with different coordinates. The upper curve is a linear plot of the data which can be made to fit a straight line after twenty minutes. The middle curve is a semi-logarithmic plot of the same data and the curve fits a straight line after the first twelve minutes. The lower curve is a full logarithmic plot, and here, all the data for the first hour can be fitted to a straight line. After the first hour the deviation from the straight line is downward. This break away from linearity is the same in all the experiments of this kind. The break was always downward and occurred between forty-five and seventyfive minutes.

$V$ - Semi-logarithmic and full logarithmic plots following rapid intravenous injection of large volumes of dyed plasma.

A large volume of dyed plasma was injected rapidly intravenously and the time-optical density relationships in arterial plasma plotted semi-logarithmically and Iogarithmically in Figure 5.

In both types of plot, the time-optical density curves were similar to those obtained with the usual small rolume injections of dye in saline.

VI - Comparison of time-optical density relationships on semi-logarithmic plots between the expected disappearance rates and observed rates following injection of undyed plasma when the time of injection of undyod plasma is varied.

In these experiments the total blood volume was kept constant by a rapid arterial hemorrhage of equal volume to the injection of undyed plasma. Figure 6A shows a fourth hour disappearance curve as a straight line on the semi-logarithmic plot. The injection of undyed plasma caused 


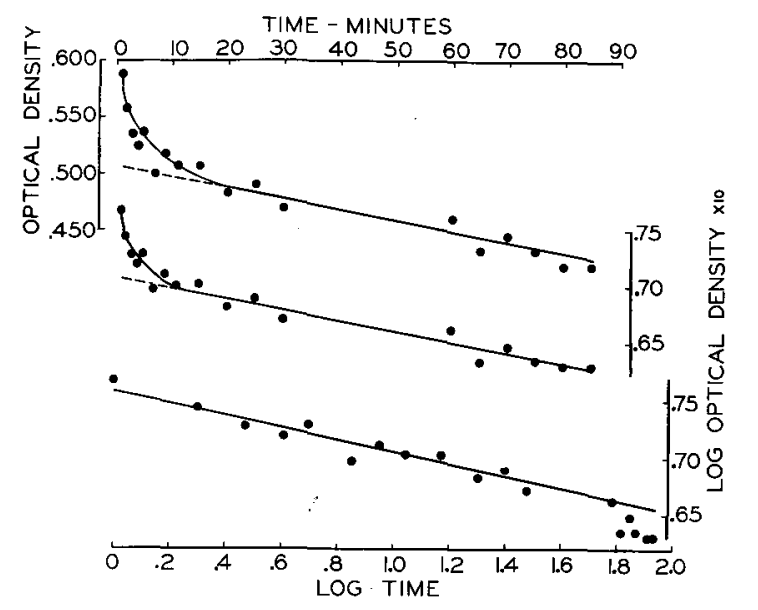

Figure 4. The uppermost curre is a Inear plot of dye concentration, as optical density, following injection of $20 \mathrm{mg}$. of the dye $\mathrm{T}-1824$. It is read against the linear scales at the left and above. The middle curre is a semi-logarithmic plot of the same data, read as the log. of optical density on the scale at the right, against the linear time scale above. The lowermost eurve shows the data plotted logarithmically, against the logarithmic scales on the right and below. 


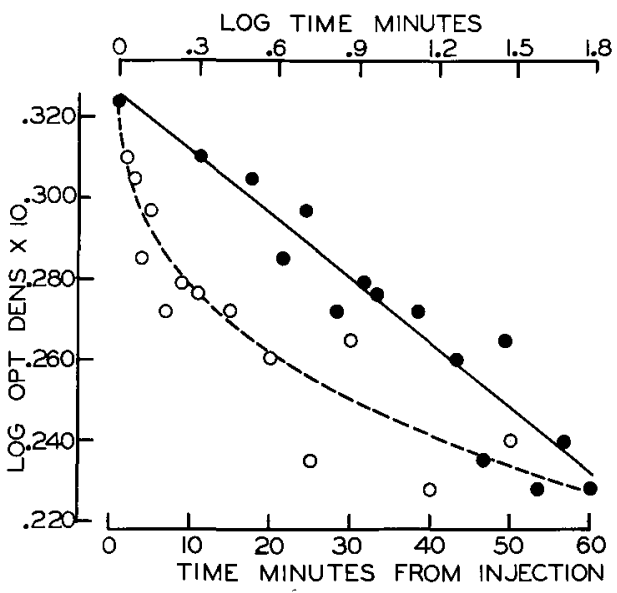

Figure 5. The filled circles and the solid line are a full logarithmic plot of optical densities folloring injection of $100 \mathrm{cc}$ of plasma containing $10 \mathrm{mg}$. of dye. To be read against the log. time scale above. The injection was preceded by withdrawal of an equal volume of blood. The open circles and the dotted line are a semi-logarithmic plot of the same data, to be read against the linear time scale below. 


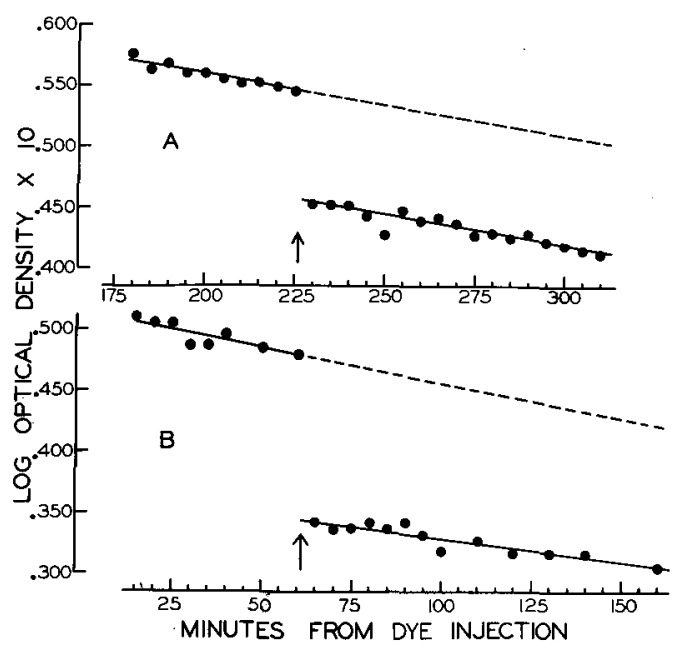

Figure 6. A. The effect of undyed plasme injection on the rate of dye disappearance during the fourth hour. The arrow marks injection of $100 \mathrm{cc}$. undyod plasme, throe and three-quarters hours after the injection of dye. The slopes of optical density have been determined by the law of least squares. The rate of dye disappearance before plasma injection is 6.90 per cent por hour, after injection, 6.89 per cent per hour.

B. The effect of undyed plasma injection on the rate of dye disappearance during the second hour. Experiment and construction of figure as in $A$, except for timing. Rate of dye disappearance before plasma injection is 7.28 per cent per hour. Rate after plasma injection is 5.25 per cent per hour. 
a decrease in dye concentration, but no detectable change in the disappearance rate as a function of the existing concentration. There was either no change or a very slight reduction in slope in all experiments of this kind when the bleeding and replacement with undyed plasmawere made several hours after the initial injection of dye. Figure $6 \mathrm{~B}$ shows the results of a similar experiment where the injection of undyed plasme was made shortly after initial dye injection. It can be seen that there is an abrupt lessening of the slope.

These results are in conformity with data obtained by following dye concentration for periods of three to four hours in undisturbed animals. During the first one to three hours following dye injection, the rate of dye disappearance decreases with decreasing concentration. The appearance of rectilinearity on semi-logarithmic plots for this period is dispelled by plotting at short intervals for longer periods, or by suddenly decreasing the concentration with a plasma infusion.

VII - Comparison of logarithmic plots of total disappearance and disappearance of "New" dye.

Figure 7 affords a quantitative comparison of the early disappearance rates following a first and second dye injection. The two "total" curves in the figure are logarithmic plots of the total dye concentration. The slope of the second injection is obviously less than the first in these plots. The second injection was made two hours after the first. During the latter half of the second hour the optical density-time relationships were plotted on semi-logarithmic paper and this plot was extrapolated through the third hour. The "Two New" curve in the figure was obtained by subtracting the extrapolated values for initial dye from the actual values obtained following the second injection of dye. This subtraction was made under the assumption that the first dye, now in its third hour, would continue to disappear exponientially while the newly injected dye was disappearing as a full 


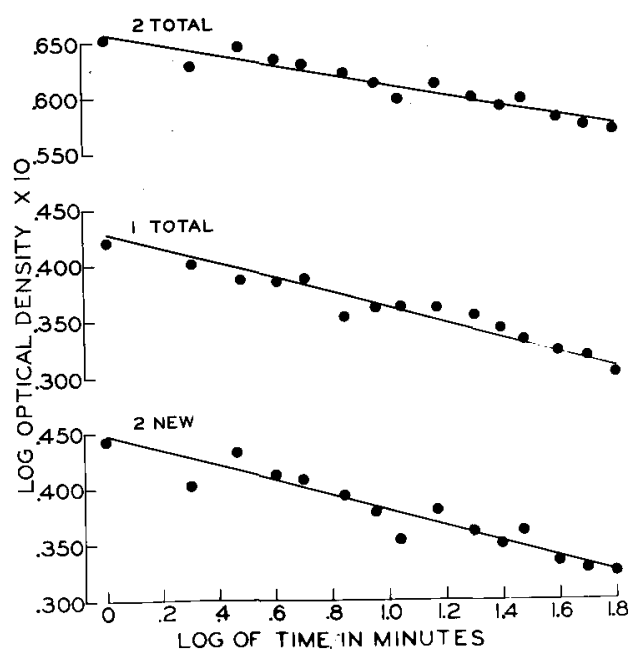

Figure 7. Early dye disappearance following a first and a second dye injection. Full logarithmic plots. Curve I (marked 1 Total) shows the optical densities following tho first injection of $10 \mathrm{mg}$. dye. One and one-half hours after the end of curve 1, densities were determined at intervals of fire minutes for an hour, and fitted to an exponential rate of disappearance (control rate of "old dye" disappearance, not shown in figure). A second injection of $10 \mathrm{mg}$. dye was then made, and the total densities plotted as curve 2 Total. In curve I Total, dye disappearance is 24.49 per cent in the first hour; in curve 2 Total, the disappearance is only 17.24 per cent. The lowermost curve (marked 2 New), was made by subtracting from each reading in curre 2 Total, the extrapolated "old dye" density 
at that time ordinate as obtained from the "old dye" control described above. The disappearance rate shown for the newly injected dye in curro 2 New is 24225 per cent in the first hour. All lines, including the "old dye" control, drawn by the law of least squares.

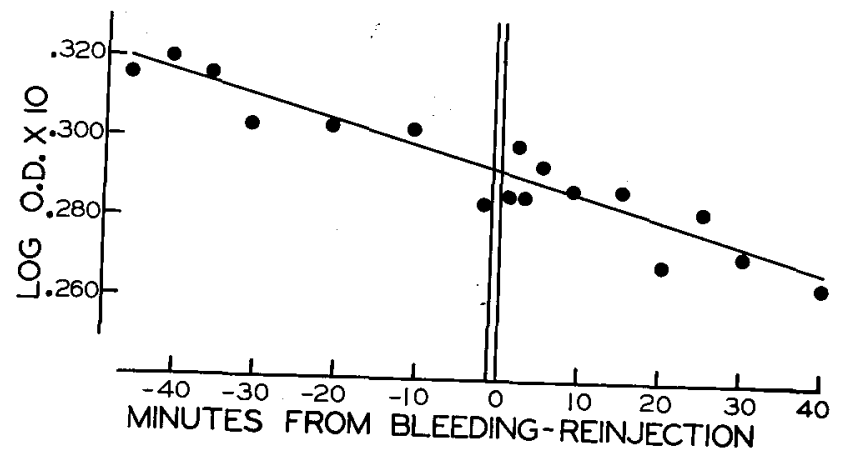

Figure 8. The effect of bleeding and reinjection on the rate of dye disappearance from arterial plasme. Twenty mg. of dye were injected at minus sixty minutes. At minus one minute approximately $10 \mathrm{cc} / \mathrm{kg}$. of blood were withdrawn from an artery into an heparinized syringe, and at time 0 this blood was reinjected into a rein. Dye concentrations are plotted semi-logarithmically as optical donsities for forty minutes before and after the bleeding and reinjection. 
logarithmic function. When the new and old dye are distinguished in this way, their disappearance rates in the first hour, as shown in the figure, are practically identical.

VIII - Bleeding and reinjection control.

Since about half of the experiments were done with pro-bleeding, the effect of a rapid hemorrhage and replacement of the same blood within a minute after the beginning of the hemorrhage was studied in a dog whose plasma had been dyed with T-1824. The animal was in a steady state and the dye was disappearing semi-logarithmically. The blood was drawn from a cannulated femoral artery into a large syringe containing a small amount of concentrated heparin solution and injected rapidly at the end of one minute into a cannulated femoral vein. The effect of this procedure on the disappearance rate of the dye is shown in Figure 8. The post-injection dye concentrations show neither an excessive deviation nor a change in rate of dye disappearance. Hematocrits obtained during the above procedure showed only random deviation from those obtained prior to hemorrhage and replacement. In other control experiments undyed animals were bled and replaced with equal volumes of autogenous undyed plasma. Plasma optical densities obtained at one minute intervals thereafter, showed no deviation from the pre-injection values.

\section{DISCUSSIOH:}

A. These data do not support the widely held belief that the phase of rapidly falling dye concentration represents "mixing" of dyed plasma in the central circuits with that in the peripheral circuits. Undyed plasma, as determined from the rising optical densities and rising arterial hematocrits, appears to mix completely within five minutes in all cases and usually within two minutes. Mixing of dyed plasma, as deternined from rising arterial 
hematocrits, is complete within five minutes and usually within two minutes. However, mixing of dyed plasme, as determined by the time required for the optical density to reach Iinearity on a semilogarithmic plot, takes from five to twenty-five minutes. In experiments where an equal volume of blood is withdrawn just prior to injection of dyed plasma, mixing time might be expected to be shortened. This is not the case. The time required for small volume injections of dyed saline to reach linearity on a semilogarithmic plot is also usually from five to twonty-five minutes. These findings seem to indicate that the continued disappearance of injected dye after five minutes represents some process other than mixing.

No consistent difference in dye loss was noted when the dye was given in small volumes of saline, or when it was given in large volumes of plasma. In adition, no consistent difference was established between the dyo losses on first and subsequent dye injections.

B. The relationship between dye-concentration and time, following the rapid intravenous injection of $T-1824$ may be expressed mathematically as:

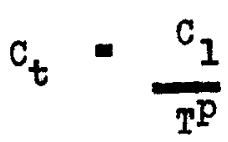

where $C_{t}$ is the dye concentration at time $t, c$, is concentration at one minute, and $\mathrm{T}^{\mathrm{P}}$ is a power, less than one, of time. All timo values in this formulation are in minutes from the injection. The average value for $p$ in a series of twenty conventional dye injections was 0.0553 , with the relativity large standard deviation of \pm 0.0117 . It is apparent that this relationship can exist for only a limited period of time. As T approaches 0 , the value of $C_{t}$ approaches infinity. Since the highest possible dye concentration is that of the injeoted solution, i.e., about $1 \mathrm{mgm} / \mathrm{cc}$, it is 
obvious that the full logarithmic plot cannot represent the data inmediately following the injection. Extrapolation to the moment of injection would require insertion of arbitrary constants in the formula, a device for which there is no justification in the present data. An attempt has been made in two experiments to determine the shape of the dye disappearance curve during the first minute, by sampling at intervals of ten seconds following the injection. Large variations were observed, which were interpreted as recirculations of the incompletely mixed column of dye. Most of the values fell above the line representing the later data in terms of the above formula. Further study of the very early. disappearance rates is needed. For the present purposes it is of minor concern that the logarithmic plot demonstrably fails to represent the date beyond the first hour. In the square root of time formula of King, Cole, and Oppenheimer (1943) an empirical time constant is employed to represent the deviation of the later data from rectilinearity. Their formula does not, however, represent the data for the first few minutes, which are assumed to be distorted by a long mixing period. Gellhorn, Morrell, and Rankin (1944) obtained a double exponiential equation which represented the change in concentration of injected $\mathrm{Na}^{24}$, and which could be adapted to the present data. The constants employed in their equation, however, were empirically determined from rates of change observed several minutes after injection. When the -quation was solved for concentration at time 0 , calculation of the plasma volume ylelded velues about twice those obtained by dye methods, suggesting that their equation did not describe the reaction during the period immediateIy following the injection.

If, as the present data show, the rate of dye disappearance changes with time, extrapolation to time 0 is likely to be extromely unreliablo, 
regardless of the method employed. The rates of change in dye concentration which are observed after the first two to five minutes may be taken to represent dye escape from the vascular system after circulatory mixing is complete. Earlier rates of disappearance from the central circulation must be influenced by mixing, and may be either greater or less for this reason. It appears that injected dye goos through the following phases: (1) An initial phase of rapid disappearance occurs during which the overall rate of disappearance from the central ciroulation is represented by a straight line on full logarithmic plot. If the rate at which previously injected dye is disappearing is substracted (Figure 7), no difference can be detected between a first and second dye injection. (2) This phase is followed by a period, lasting one to three hours, during which the rate of disappearance gradually declines with the decrease in concentration. If undyed plasma is injected during this period, to produce a decrease in dye concentratian, the rate of dye disappearance is decreased, (Figure 6 B). (3) There is a subsequent period during which the rate of disappearance seems to be a fixed percentage of the existing dye. This exponential rate of disappearance is not changed by sudienly decreasing the dye concentration (Figure $6 \mathrm{~A}$ ). Disappearance rates at still later intervals were not studied. The identity of behavior of a first and a seoond dye injection, when allowance is made for the changing rate of disappearance with time, is at variance with the report of Cruickshank and Whitfield (1945).

The fact that each new dye injection must pass through a phase of rapid disappearance is, of course, what would be expected if the dye were lost from the plasma compartment into a space which reaches a state of equilibrium with plasma fairly soon. 
INTRODUCTION

PART II 


\section{INTRODUCTION}

\section{PART II}

A. Measurement of plasma volume as the distribution volume of injected autogenous plasma.

The data presented in Part I of this paper indicate that the initial excessive rate of disappearanoe of injected dye is not due to mixing within the cordiovascular system. This is indirect evidence that the Gibson and Evans method for determining plasma volume yields values that were too high. Other observations (Stead and Ebert, 194I; Lawson, Rappaport, and Ramirez 1946; Neneely, Wells, and Hahn 1947) indicate thet plasma rolume as determined by the method of Gibson and Evans is overestimated. None of these studies, however, offer an independent estimate for plasma volume which was more reliable.

It seemed feasible to attempt to determine plesma volume from the amount of dilution of dyed ciroulating plasma with known volumes of undyed autogenous plasma. Control experiments have shown that such plasma injections do not change the rate of dye disappearance if given at a sufficiently long interval following the dye infection. There is, furthermore, no evidence that the dye which has been lost from the plasma compartment returns in any appreciable amount. Errors in the dye injection method due to dyo escape during the early phases should not be present in the dye dilution method for the se reasons. No assumptions are de regarding the actual amount of circulating dye, except that it is not ohanged by the plasma injections.

The dilution of normal plasma constituants by injection of largo volumes of crystalloidal or foreign colloidal solution was employed by De Crinis (1917) and Loewy (1920). There was no assurance that the 
injected substances would remein in the cardiovascular system in these cases. Furthermore, many large technical errors were inherent in the method. In the present study, percentage technical errors are reduced by injecting enough dye to give the circulating plasma a high optical density and by using undyed autogenous plasma for the dye dilution in sufficient volume to give a 15 to 30 per cent decrease in the circulating dye cancentration. It is assumed that the autogenous plasma will undergo minimal changes in volume within the circulation. In some of the earlier experiments with the dye dilution method the undyed plasma was rapidiy injected after the circulating dyod plasma was in a steady state and disappearing from the arterial plasma at an exponential rate. In these experiments the blood volume was increased about $10 \mathrm{cc} / \mathrm{kg}$. and the post-injection optical densities of the arterial plasma varied in such a manner that extrapolation to the instant of injection was difficult. In all the later experiments, the attempt was made to keep blood volume constant by preceding the plesma injection by a rapid arterial hemorrhage equal in volume to the injection. 
MeTHODS 
METHODS

Barbitalized, splenectomized dogs were used and autogenous heparinized plasma was obtained as described in Part I. Hemorrhage, infusion of autogenous plasma and the drawing of samples were done as described in Part I. Circulating plasm was dyed with a dose of T-1824 large enough to give plasma dye concentrations of the order of 0.025 to $0.035 \mathrm{mgm} / \mathrm{cc}$. One to four hours later approximately $10 \mathrm{cc} / \mathrm{kg}$. of blood was rapidly drawn from a cannulated femoral artery. This was immodiately followed by the rapid infusion of an equal volume of undyed autogenous plasma. The total time for hemorrhage and infusion was generally of the order of one minute or loss. Samples of circulating plasma were taken at frequent intervals following the hemorrhage and infusion in order to determine and to compare plasma volume as determined by the Gibson and Evans, the full logarithmic, and the dye dilution methods.

The calculation of plasma volume is besed on the assumption that the optical density of the mixture of dyed and undyed plasma in the ciroulation after injection of the latter is simply the mean of the two densities as moasured before the injection. Under the se conditions:

$$
\text { P. V. }=\frac{V_{r} \times\left({ }_{m}^{E}-{ }^{E} r\right)}{E_{p}^{-E} m}+P_{\theta}
$$

where $P \cdot V$. is the circulating plasma volume inmediately before the hemorrhage and replacement, $V_{r}$ is the volume of injected plasma, $E_{p}$ is the optical density of the circulating plasma at the instant of hemorrhage, 
$\mathrm{E}_{\mathrm{m}}$ is the optical density of the mixture after the injection, and $\mathrm{E}_{\mathrm{r}}$ the optical density of the injected plasma. Since the rolume of the circulating plasma volume at the instant before hemorrhage is to be determined it is necessary to add the volume of plasma drawn during the hemorrhage, $P_{\theta}$. If this is not done, the oquation solves for the circulating plasma volume at the end of the hemorrhage. If all the optical densities are read against an undyed plasma reference, and autogenous plasma is used, $E_{r}$ drops out of the equation. In those experiments where no hemorrhage preceded the infusion, the value $P_{e}$ was left out of the equation which then solved for P.V. at the instant before injection. Figure 9 shows the type of data obtained. $E_{p}$ and $E_{m}$ are read at the completion of plasma injection by extrapolation of the two optical density curves. It is essential for the accuracy of this method that the blood volume remain the sane for a short while after the homorrhage and infusion as it was prior to this procedure. 


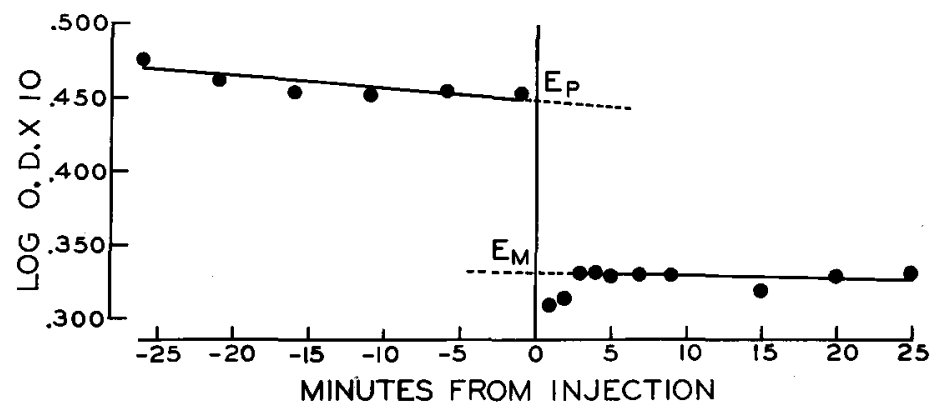

Figure 9. Measurement of plasma volume by dye decrement. At time 0,100 cc. undyed plasm were injected, following withdrawal of 100 cc. blood. The extrapolations yield $E_{p}=0.2806$, and $E_{m}=0.2143$ (antilogs.). Since the opticel densities were read against undyed plasma as a reference, $\mathrm{E}_{\mathbf{r}}=0$. Plasma volume (see text) is thus: PV $=\frac{100-0.2143}{0.2806-0.2143}=323 \mathrm{cc}$. In this experiment there appears to be a three-minute mixing period for the injected plasma. 
RESULTS 


\section{RESULTS}

The ossential data are given in table 1., which shows comparative values for plasma volume obtained as follows:

(1) By the dye injection mothod of Gibson and Evans as P.V $=\frac{D}{c}$, where $D$ is the amount of dye injected, and $c$ is the concentration at $t$ ime 0 obtained by extrapolating the approximately exponential segment of the time-concentration curve plotted after the first fifteen minutes. By the same formula, substituting for c in the above formula the dye concentration read at one minute on the full logarithmic smoothod plot which was described in Part I. This value will be referred to as the one minute dye volume. (3) By the subsequent injection of undyed plasma as described in the foregoing. This will be called the dye-decrement volume.

The table shows that the apparent distribution volume of the dye, at one minute following its injection, is usually very similar to the distribution volume of injected undyed plasma. Both of these volumes are consistently smaller than the plasma rolume as obtained by the method of Gibson and Evans. Where there is any appreciable difference between the one-minute dye volume and the dye-decrement volume, the oneminute volume is always larger. This would be expected if same dye has escaped from the plasma compartmont within the first minute.

Figure 10 shows the agreement between the one-minute dye volumo and the dye-decrement volume in another form. If Gibson and Evans' interpretation of the time-concentration curves for dye is correct, the distribution volume of dye within the vascular system is expanding throughout the initial phase of fast disappearance. In the construction of Figure 
Comparative values for plasma volume. The values given under the heading $G$ \& $E$ were obtained with the dye method of Gibson and Evans. The column headed 1-min. dye gives values obtained by substituting the concentration of dye observed at one minute in the Gibson and Evans' celculation. The values listed under Dye decrement were obtained with undyed plasma injection as described in the text. The last throe colums give the ratios of these comparative values. Dye decrement values for dogs 11 and 12 were obtained without bleeding before the injection, all others with bleeding (see text). All rolumes are givon in cubic centimeters.

\begin{tabular}{|c|c|c|c|c|c|c|}
\hline Dog no. & $G \& E$ & $\begin{array}{c}1-\min . \\
\mathrm{dy} \theta\end{array}$ & $\begin{array}{c}\text { Dye } \\
\text { decrement }\end{array}$ & $\begin{array}{l}1-\min . / \\
G \& \mathrm{E} .\end{array}$ & $\begin{array}{l}\text { Dye dec./ } \\
\text { G \& E }\end{array}$ & $\begin{array}{l}\text { 1-min./ } \\
\text { dye dec. }\end{array}$ \\
\hline $\begin{array}{r}1 \\
2 \\
3 \\
4 \\
5 \\
6 \\
7 \\
8 \\
9 \\
10 \\
11 \\
12\end{array}$ & $\begin{array}{l}414 \\
500 \\
470 \\
650 \\
552 \\
370 \\
346 \\
576 \\
380 \\
489 \\
620 \\
545\end{array}$ & $\begin{array}{l}370 \\
454 \\
395 \\
567 \\
491 \\
341 \\
308 \\
498 \\
338 \\
410 \\
534 \\
446\end{array}$ & $\begin{array}{l}363 \\
411 \\
361 \\
570 \\
490 \\
345 \\
296 \\
466 \\
335 \\
385 \\
532 \\
454\end{array}$ & $\begin{array}{l}0.894 \\
0.907 \\
0.840 \\
0.872 \\
0.890 \\
0.921 \\
0.390 \\
0.866 \\
0.890 \\
0.840 \\
0.861 \\
0.818\end{array}$ & $\begin{array}{l}0.878 \\
0.823 \\
0.768 \\
0.876 \\
0.888 \\
0.933 \\
0.856 \\
0.308 \\
0.882 \\
0.788 \\
0.858 \\
0.833\end{array}$ & $\begin{array}{l}1.019 \\
1.102 \\
1.094 \\
0.994 \\
1.001 \\
0.989 \\
1.039 \\
1.069 \\
1.008 \\
1.064 \\
1.004 \\
0.984\end{array}$ \\
\hline
\end{tabular}

Ave.

$\underline{0.874 \quad 0.849 \quad \underline{1.031}}$




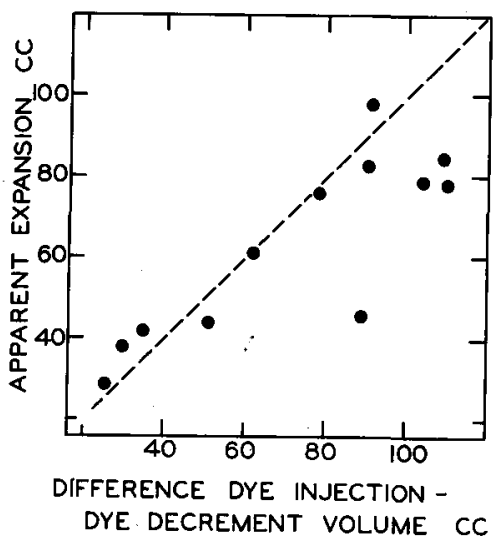

Figure 10. The ordinates show the apparent expansion of the dye distribution volume during the "mixing period", calculated fram $\frac{D}{C}-\frac{D}{C I}$, where $D$ is the amount of dye injected, $c_{10}$ is the concentration at one minute obtained by extrapolating the later exponiential slope, and $c_{1}$ is the actual concentration at one minute read on the $\log _{--10 g}$. smoothed plot. The abscissae show the difference between the conventional dye-injection value for plasma rolume, and the volume obtained by the dye-decrement method. The dashed line is drawn at perfect agreement. 
2 the apparent expansion during this period is obtained for our experiments as $\frac{D}{{ }_{10}}-\frac{D}{C_{1}}$ where $D$ is the amount of dye injected, $c_{10}$ is the concentration at one minute on Gibson and Evans' exponential extrapolation. and $c_{1}$ is the actual concentration at one minute on the full logarithmio smoothed plot. The differences between the Gibs on and Evans and dyedecrement values are in very good agreement with the apparent expansion of the dye distribution volume during the rapid disappearance phase. It is difficult to explain this correlation on the basis of any systematic error in the dye-decrement method. If, on the other hand, the dyedecrement method yields a more nearly true value for plasma rolume, this correlation would be expected. The error in the volume obtained by Gibson and Evans' method should be a function of the dye lost from the plasm compartment during the initial rapid disappearance phase.

Controls on the validity of the dye-decrement method were obtained by using dyed plasma rather than undyed in otherwise identical experiments. Table 2 shows the values obtained for plasma volume by the injection of dyed autogenous plasma as compared with small volume injections of highly concentrated dye solutions. The dyed plasma was converted to total dye injected and the volume of plasma injected was substracted from the resultant plasme volume. In all the experiments, the values obtained with dyed plasme agreed within $7 \%$ with the value obtained by the conventional dye-injection method. The disagreements were random in direction, with an average for the group of only $1.5 \%$ difference. 
Comparative values for dye distribution when injected in a large volume of plasma and a small volume of aqueous solution (saline). The values given under the heading Dye are the dye distribution volumes obtained by the method of Gibson and Evans with injection of 10 to $20 \mathrm{cc}$. of conventional dye solution. The values given under Dyed plasma are the dye distribution volumes obtained by the same calculation (seo text) with the injection of 100 to $150 \mathrm{cc}$. of dyed plasma (10 cc./ kg.), after correction for the volume of plasma added to the olrculation. All volumes are given in oubic centimoters.

Dog no. Dyo Dyed plasma Dyed plasma/ Experimental condition dye

\begin{tabular}{|c|c|c|c|c|}
\hline $\begin{array}{l}13 \\
14\end{array}$ & $\begin{array}{l}461 \\
654\end{array}$ & $\begin{array}{l}489 \\
660\end{array}$ & $: \begin{array}{l}1.059 \\
1.010\end{array}$ & $\begin{array}{c}\text { Dyo first, bloeding } \\
\text { Dyed plasme first, } \\
\text { no bloeding }\end{array}$ \\
\hline 15 & 532 & 514 & 0.966 & $\begin{array}{c}\text { Dyod plasma first, } \\
\text { no blooding }\end{array}$ \\
\hline 16 & 530 & 502 & 0.950 & $\begin{array}{c}\text { Dyod plasme first, } \\
\text { bleoding }\end{array}$ \\
\hline $\begin{array}{l}17 \\
18 \\
19\end{array}$ & $\begin{array}{l}558 \\
362 \\
349\end{array}$ & $\begin{array}{l}554 \\
379 \\
327\end{array}$ & $\begin{array}{l}0.992 \\
1.047 \\
0.933\end{array}$ & $\begin{array}{c}\text { Dyo first, no bleoding } \\
\text { Dye first, no bleoding } \\
\text { Dyed plasma first, } \\
\text { bloeding }\end{array}$ \\
\hline
\end{tabular}


DISCUSSION 


\section{DISCUSSION}

The control studies with dyed plasma injection fail to reveal any systemic error in the dyo-decrement method. Circulatory disturbances or errors in the basic assumptions, capable of producing a systemic difference between the dye injection volume and the dye-decrement volume, should also systematically influence the apparent distribution volum of injectod dyed plasma. In the control studies, however, the distribution volume of dyed plasme is not consistantly different from that of dye injected in the usual manner. It seems unlikely that the presence or absence of dye in the injeoted plasme will actually influence the distribution of the plasma within the circulation therefore, the difference between dyed and undyed plasma most probably means that dye loaves the latter to distribute itself beyond the plasma compartment.

The time-concentration curves are treated in exactly the same manner in these studies, in obtaining the dye-injection and dye-decrement volume. For both calculations an exponential post-injection slope is extrapolated to the time of injection to obtain the change in optical density after complete mixing and before loss of injected material. The calculations are fundamentally identical and based on identical assumptions. Both assume a constant rate of change to begin at the time of injection with the possibility of masking during an initial mixing period. This period of mixing usually lasts two minutes or less in the dye-decrement method. It lasts from five to twenty-five minutes in the dye injection mothod. The assumption of a constant rate of change thus comes closer to empirical verification with the dye-decrement method. The qualitative data presented in Part I and the quantitative controls in Part II seem to indicate that the dye-docrement plasma volumes are more reliable than the dye 
dilution plasma volumes.

Early dye methods of plasme volume determination allowed a supposedly minimum time for circulatory mixing, usually of the order of three minutes, and samples were draw as soon as possible thereafter in order to minimize dye loss (Keith, Roundtre日, and Geraghty, 1915). The empirical agreement in the present studies between the one minute dye volumes and the dyedecrement volumes suggests that the former may be useful in obtaining an approximate value for plasma volume. The agreement, however, may be simply fortuitous. Mixing of plasm solute is not always complote within one minute and also the injected dye may disappear from the ciroulation before mixing is camplete in quantities large enough to introduce other errors in plasma volume determinations. It is possible that the se two processes sumate in such a way as to yield a true value for plasma volume. 
SUMMARY 
SUMARARY

PART I

A. Mixing of red cell suspensions, plasme, and the dye T-1824 within the cardiovascular system of barbitalized dogs was studied. In some experiments the blood volume was kept constant and in others it was expanded. Mixing of injected cell suspensions and autogenous plasma. as determined by the time required for the post-injection hematocrits to reach a steady state, was never longer that 5 minutes and usually less than 3 minutes.

Mixing of undyed autogenous plasma in the cardiovascular system of dogs that had had their plasma previously dyed (with $T-1824$ ) was usually complete within 3 minutes. This was determined as the time required for the post-injection optical densities to reach linearity on a semilogarithmic plot. Mixing of dye in saline or autogenous dyed plasma required from five to twenty-five minutes. This was determined as the time required for the post-injection optical densities to reach linearity on a semilogarithmic plot. No consistent difference in the time for mixing of dye was noted when it was injeoted in high conoentrations in a small volume of saline or when it was given in low concentration in relatively large volumes of plasma. No significant difference was observed when the injection was preceded by an equivalent blood withdrawal.

It is concluded from the foregoing data that the mixing time for cells and plasme is of the order of 5 minutes under the described experimental conditions. The continued rapid disappearance of injected dye bey and the first 5 minutes, cannot be explained as being due to mixing of plasma from the central circulation with the peripheral. This seems to be explained best by the passage of dye outside the vascular system. 
B. When the dye $T-1824$ is injected intravenously into barbitalized splenectomized dogs, arterial dye concentrations from one to approximately sixty minutes after injection decrease in accordance to the relationship: $c_{t}=\frac{C_{1}}{T^{p}}$, where $C_{t}$ is the concentration at any one minute, $T$ is time in minutes from the injection, and $p$ is a fractional power. The average value found for $p$ in twenty dye injections was 0.0553 , standard deviation \pm 0.0117 . The fact that the dye concentration-time relationship is linear on full logarithmic plots for approximately an hour after injection is useful for smoothing the values during the phase of rapidly falling dye concentration. This aids in the quantitative study of dye disappearance during the first hour.

Evidence is presented which indicates that disappearance of the dye T-1824 occurs in three phases. The first is characterized by rapid disappearance and lasts for approximately one hour. During this phase the logarithm of dye concentration is a linear function of the logarithm of timo. This is followed by a transition phase lasting from one to three hours. The third one is an exponential phase in which the logarithm of dye concentration is a linear funotion of time. Each new dye injection appears to go through these three:phases. 
SURAARY

PART II

A method for determining plasm volume from the dilution of dyed plasma with autogenous undyed plasma is described. Values for plasma volume in barbitalized dogs obtained by the method of Gibson and Evans with the dye T-1824 were compared with those obtained with the autogenous plasma infusion mothod (dye-decrement mothod). The dye-decrement values averaged approximately $85 \%$ of the dye distribution volume in a series of twelve animals, with extremes of 77 and $93 \%$. When control experiments were performed using dyed rather than undyed plasma, the plasma rolumes obtained were in good agreement with those obtained with small volumes of concentrated dye solution.

When plasme volume was estimated from the dilution volume of the injected dye at one minute on a full logarithmic smoothed plot of the rapid disappearance phase, the values were found to be in fairly good agreement, as a rule, with the dye-decrement volumes. When a large amount of dye disappeared from arterial plasma during the rapid disappearance phase, the apparent distribution volume of the dye as obtained by the method of Gibson and Evans was greatly in excess of the distribution volumo of undyed plasma. Whon only a small dye disappearance was observed, the two distribution volumes were more nearly in agreement. 
REFEREN CES 
1. Chapin, M. A. and J. F. Ross. American Journal of Physiology 137: 447, 1942 .

2. Cruickshank, E. W. H. and J. C. Whitfield. Journal of Physiology $104: 52,1945$.

3. De Crinis, M. Zeitschr f. Physiol. Chem. 99: 131, 1917.

4. Erlanger, J. Physiol. Rev 1: 177, 1921.

5. Ferrebee, J. W., O. C. Leigh, and R. W. Berliner. Proc. Soc. Expr. Biol. and Med. 46: 549, 1941.

6. Gellhorn, A., M. Merrell, and R. M. Rankin. Am. J. Physiol $142: 407,1944$.

7. Gibson, J. G. and W. A. Evans. J. Clin Invest, 16: 301, 1937.

8. Hahn, L. and G. Hevosy. Acta. Physiol. Scand. 1: 3, 1940.

9. Hahn, P. F., J. F. Ross, W. F. Bale, W. M• Balfour, and G. H. Whipple. J. Exper. Med. 75: 221, 1942.

10. Hamilton, W. F., J. W. Moore, J. M. Kinsman, and R. G. Spurling. Am. J. Phýsiol. 84: 338, 1928.

11. King, B. G., K. S. Cole, and E. T. Oppenheimer. Am. J. Physiol. 138: $636,1943$.

12. Lawson, H. C., D. T. Overbey, J. C. Moore, and O. W. Shadlo. Am. J. Physiol. (in press), 1947.

13. Laws on, H. C., D. B. Rappaport, and A. Rameriz. Am. J. Physiol. $147: 412,1946$

14. Laws on, H. C., O. W. Shadle, J. C. Hoore, and D. T. Overbey. Am. J. Physiol. (in press), 1947.

15. Loewy, J. Zentralb. f. inn. Mod. 4l: 337, 1920. 
16. Menoeley, G. R., E. B. Wells, and P. F. Hahn. Am. J. Physiol. 148: $531,1947$.

17. Miller, A. T. Fed. Proo. 6: 166, 1947.

18. Overbey, D. T., J. C. Moore, O. W. Shadle, and H. C. Lawson, Am. J. Physiol. (in press), 1947.

19. Smith, H. P. Bull. Johns Hopkins Hosp. 36, 325, 1925.

20. Smith, H. P. J. Exp. Mod. 51: 379, 1930.

21. Stead, E. A., and R. V. Ebert. Am. J. Physiol. 132: 411, 1941.

22. Stewart, G. N. Am. J. Physiol. 58: 20, 1921. 


\section{David T. Overbey}

The Dye-Dilution Method for Moasuring the

Volume of Circulating Plasma

Approved by Reading Cormittee composed of the following members:

John Walker Moore

Warren S. Rehm

Hampden Lawson

1948 